\title{
Knowledge, awareness, perception, and willingness towards eye donation among the literate working population
}

\author{
Justin Egnasious', Krithica Srinivasan', Ramesh S. Ve', \\ Babu Noushad' \\ 'Department of Optometry, School of Allied Health Sciences, Manipal Academy of \\ Higher Education, India
}

\begin{abstract}
Aim: To evaluate awareness, knowledge, and perception towards eye donation among the literate working population.

Methods: A new questionnaire on eye donation was developed from existing literature and face validation was performed, among subject experts. Repeatability of the questionnaire was performed among 30 subjects.

There was a total of 23 questions: six questions for evaluating awareness, 13 questions for evaluating knowledge, and four questions for determining the subjects' perception. The questionnaire was distributed among subjects working in both the health science and non-health science fields. From their responses, knowledge, awareness, and perception towards eye donation in the working literate population were assessed. A pledge form was also handed out along with the questionnaire to assess the subjects' actual willingness. Results: The questions in the awareness and knowledge domain showed good repeatability $(p>0.05)$. More than $50 \%$ of the parameters in the perception domain showed poor repeatability $(p<0.05)$. Out of 189 subjects assessed, there were 97 health science and 92 non-health science subjects with total mean age $30 \pm 7$ years. Good awareness was present between health science (96\%) and non-health science (94\%). Only $21 \%$ of the health science and $11 \%$ of the non-health science group had good knowledge about eye donation. Only $25 \%$ said 'yes' to willingness about eye donation. However, only $3 \%$ filled out the pledge form. No-one from the non-health science group filled out the pledge form. Health science professionals showed more willingness to donate eyes compared to the non-health science group after adjusting for qualification, age, and gender (odds ratio $2.158, p=0.031,95 \% \mathrm{Cl}(1.073,4.341))$. Study participants shared willingness to donate eyes and responded against negative perceptions such as 'Family members object to eye donation' (odds: 3.75, $p=0.030,95 \% \mathrm{Cl}(1.14,12.39)$ ), 'Dislike of separating eye from the body' (odds:7.02, $p=0.006,95 \% \mathrm{Cl}(1.73,28.42))$, and 'Donating an organ is against my religious belief' (odds: $8.51, p=0.039,95 \% \mathrm{Cl}(1.11,65.09))$.
\end{abstract}

Correspondence: Krithica Srinivasan, Department of Optometry, School of Allied Health Sciences, Manipal Academy of Higher Education, Manipal-576104, Karnataka, India.

E-mail: skrithica@yahoo.com 
Knowledge, awareness, perception, and willingness towards eye donation among the literate working population

Conclusion: Our study showed that education qualification and the perception like 'eye donation is against religious beliefs' and 'dislike to separate eye from the body' showed significant effect on the willingness to donate eyes. More than awareness and knowledge, perception about eye donation had more impact on the willingness to donate eyes. Therefore, more campaign emphasizing the importance of eye donation need to be conducted to change the perceptions about eye donation rather than improving awareness or knowledge.

Keywords: Awareness, eye donation, knowledge, literates, perception

\section{Introduction}

In India, 12 million people have visual impairment, which is the largest number of visually impaired people in any country. ${ }^{1}$ One hundred and ninety thousand people are bilaterally blind and over 600,000 have unilateral blindness. ${ }^{1}$ Corneal disorders are the principal cause of blindness among this population. This could be treated by corneal transplant surgery; nearly one million people are in need of corneal transplant. ${ }^{2}$ The annual donation of corneas in India has been reported to be as low as 22,000 . In contrast, Sri Lanka, which has a smaller population, has a greater amount of eye donation. ${ }^{3}$

Knowledge on the use of donated eyes was very poor despite the reasonable awareness campaign of eye donation. There are almost 52 million visually impaired people and 270,000 blind children in India ${ }^{6}$ - which means almost one-fourth of the world's blind population lives in India. The reason for inadequate eye donations need not necessarily be awareness. There could be also other factors like physical, cultural, or psychological barriers. The causes may vary based on subjects' educational status, profession, etc. Therefore we aim to evaluate knowledge, awareness, and perception towards eye donation among health science and non-health science professionals.

\section{Methods}

The study was approved by the Institutional Review Board. Informed consent was obtained from all the subjects. This cross-sectional study was based on a self-administered questionnaire survey. Based on the available literature, a questionnaire was developed and face validation was performed among subject experts. The questionnaire mainly consists of three domains: awareness, knowledge, and perceptions. It consisted of a total of 23 questions: six questions for evaluating awareness, 13 questions to evaluate knowledge, and four questions about the subjects' perception.

'Awareness' was defined as knowing terms such as eye donation, eye banks, and when eye donation can be done. 'Knowledge' was considered as understanding the details of different aspects of eye donation like pledging of eyes, who can donate eyes, when can eyes be donated, and what steps are to be taken after death to donate one's eyes.

To assess the repeatability of the questionnaire, it was administered twice to a group of health science faculty members in a two-week time frame. Along with 
the questionnaire, an eye pledge form was also given during the main survey. They were requested to fill out the pledge form if they were willing to donate their eyes. Participants filled out the questionnaire in the absence of the investigator.

Those who were willing to participate were included in the study. Subjects with health science professions belonged to medical faculties or nursing college; subjects with non-health science professions were non-teaching staff of the university, bank employees, and lawyers. The educational levels, age, and gender in either group were matched based on the highest degree of eligible participants. Faculty members and their relatives from the Optometry and Ophthalmology departments were excluded on the basis that they have sufficient awareness and knowledge about eye donation.

Data analysis was done using SPSS v16.0. The Kolmogorov Simonov test was used to test the normality of the data. Wilcoxon sign rank test was used to check the repeatability of the questionnaire. Depending upon the distribution of data either the Mann-Whitney test or the unpaired t-test was used to compare the awareness and knowledge between the health science and non-health science group. Univariate logistic regression was performed to find the variables associated with willingness to donate eyes.

\section{Results}

\section{Repeatability}

Repeatability was done among 30 subjects (63\% females and $37 \%$ males) with a mean (SD) age of 32 (9) years. Since the data does not follow normal distribution, a Wilcoxon Signed Ranks test was done to analyze the repeatability of response for every question in all three domains: awareness, knowledge, and perceptions. The questions in awareness and knowledge domain showed good repeatability ( $p>$ $0.05)$. More than $50 \%$ of the parameters in the perception domain showed poor repeatability $(p<0.05)$. The perceptions for which the repeatability was poor and the corresponding $p$-values are given in Table 1.

Table 1. Repeatability of perceptions about eye donation.

\begin{tabular}{|l|c|c|}
\hline Questions & IQR (Q3-Q1) & p-value \\
\hline Dislike of separating eye from body & 1 & 0.017 \\
\hline Feel unsuitable to donate eyes because of age & 2 & 0.015 \\
\hline $\begin{array}{l}\text { Feel unsuitable to donate eyes because of health } \\
\text { problems }\end{array}$ & 2 & 0.003 \\
\hline $\begin{array}{l}\text { Eye donation will delay funeral and other } \\
\text { religious rites after death }\end{array}$ & 0.25 & 0.039 \\
\hline $\begin{array}{l}\text { Signing an eye donor card feels like signing a } \\
\text { death certificate }\end{array}$ & 1 & 0.017 \\
\hline
\end{tabular}


Knowledge, awareness, perception, and willingness towards eye donation among the literate working population

\section{Main survey}

One hundred and eighty-nine subjects participated in the main survey. There were 97 health science subjects and 92 non-health science subjects with a mean (SD) age of 30 (7) years. The demographic details of the participants are given in Table 2.

Table 2. Demographic details.

\begin{tabular}{|l|c|c|c|c|c|c|c|}
\hline & & & & \multicolumn{3}{c|}{ Qualification \% } \\
\cline { 5 - 8 } & $\begin{array}{c}\text { Age in years } \\
\text { (mean } \pm \text { SD) }\end{array}$ & $\begin{array}{c}\text { Female } \\
\%\end{array}$ & Male \% & PhD & Masters & Bachelors & Diploma \\
\hline $\begin{array}{l}\text { Health } \\
\text { science }\end{array}$ & $29 \pm 7$ & 67 & 33 & 6 & 45 & 40 & 9 \\
\hline $\begin{array}{l}\text { Non-health } \\
\text { science }\end{array}$ & $29 \pm 7$ & 67 & 33 & 6 & 45 & 40 & 9 \\
\hline
\end{tabular}

The awareness and knowledge scores were calculated as follows: right answers, 1 ; wrong answers, -1;'Don't Know', 0 . Based on the sum of these scores in each domain, the total awareness and knowledge scores were calculated.

The awareness percentage was calculated and categorized as above and below $50 \%$. Since we had negative scoring in the knowledge domain, the knowledge level was categorized as greater than or equal to $50 \%, 0$ to less than $50 \%$, and below $0 \%$. The level of awareness and knowledge in the health science and non-health science groups is shown in Table 3.

Table 3. Awareness and knowledge percentage.

\begin{tabular}{|l|l|l|l|}
\hline Parameter & Percentage & Health science (\%) & $\begin{array}{l}\text { Non-health science } \\
(\%)\end{array}$ \\
\hline \multirow{2}{*}{ Awareness } & $\geq 50$ & 96 & 94 \\
\cline { 2 - 4 } & $<50$ & 4 & 6 \\
\hline \multirow{2}{*}{ Knowledge } & $\geq 50$ & 21 & 11 \\
\cline { 2 - 4 } & $0 \geq x \geq 50$ & 72 & 65 \\
\cline { 2 - 4 } & $<0$ & 7 & 15 \\
\hline
\end{tabular}

Awareness scores between the health science and non-health science groups were analyzed using Wilcoxon Signed Ranks as the data was not normally distributed and found that there were no significant difference between the two groups $(p=0.627)$. Knowledge scores between the two groups were analyzed using the unpaired T-test as the data was normally distributed and found that there was statistically significant difference between two groups $(\mathrm{p}=0.041,95 \% \mathrm{Cl} 0.37,1.72)$.

There was no significant difference in willingness towards eye donation between the two groups $(p=0.407)$. The percentage of participants who said 'yes' to eye donation was $32 \%$ and $19 \%$ in the health science and non-health science groups, 
respectively. Almost $40 \%$ of people in both groups said they needed time to decide whether or not to pledge eyes. None of the participants in the health science and non-health science groups answered 'yes' to the question about willingness of donating the eyes of a close relative on their death. There was no significant difference in knowledge level between males and females both in the health science ( $p$ $=0.673)$ and non-health science $(p=0.329)$ groups using unpaired t-test.

Along with the questionnaire, a pledge form was also given to the respondents. The participants were not compelled to fill out the pledge form; it was left to their discretion. Willingness to complete the pledge form is given in Figure 1.

\section{Figure 1: Willingness to pledge eyes}

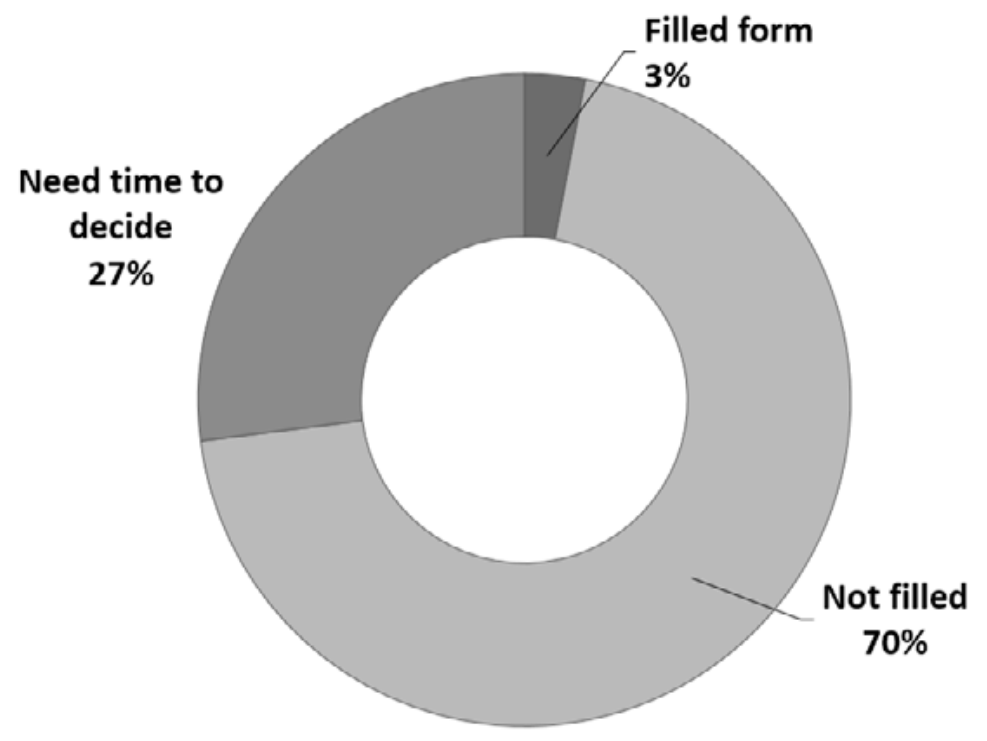

Fig. 1. Willingness to pledge eyes. Among the $3 \%$ who have filled out the questionnaire, all belonged to the health science group. Of the subjects in both groups, $70 \%$ agreed that lack of awareness about eye donation and family members' objection towards eye donation are the major reasons for not donating eyes ( $62 \% \mathrm{HS}$ and $70 \% \mathrm{NHS})$.

The bar diagram in Figure 2 explains the difference in perception regarding the donation of eyes among the health science and non-health science groups. Among various perceptions, a significant difference between the two groups was found for four perceptions shown in Figure 2.

Mass media was the most common source of information on eye donation for both health science (72.2\%) and non-health science (68.5\%) subjects, followed by hospital and family doctor. Beyond mass media television, the major sources were newspaper and radio. 
Knowledge, awareness, perception, and willingness towards eye donation among the literate working population

Twenty percent in the health-science and $13 \%$ in the non-health science group said that there is an age limit for eye donation. The upper limit of 60 years was given by $35 \%$ of all the participants who answered there is an age limit. At least one eye bank in India was named by $33 \%$ and $25 \%$ of the health and non-health science groups, respectively.

Thirty-eight percent of the participants did not answer the question regarding ways to increase eye donation awareness. Of the others, many suggested advertisements in mass media and conducting awareness campaigns as major sources to increase awareness. Including eye donation in curriculum was also mentioned as a method to increase the awareness.

Binary logistic regression was done to find out the association between willingness and age, gender, and qualification. Without adjusting for any factors, it showed that the odds of health science professionals for pledging eyes was two times higher than non-health science professionals, but this was not statistically significant. When adjusted for age and gender there was not much change in the odds ratio either. However, when adjusted for educational qualification, the odds ratio increased to $2.158(p=0.031,95 \% \mathrm{Cl}(1.073,4.341))$, which was statistically significant.

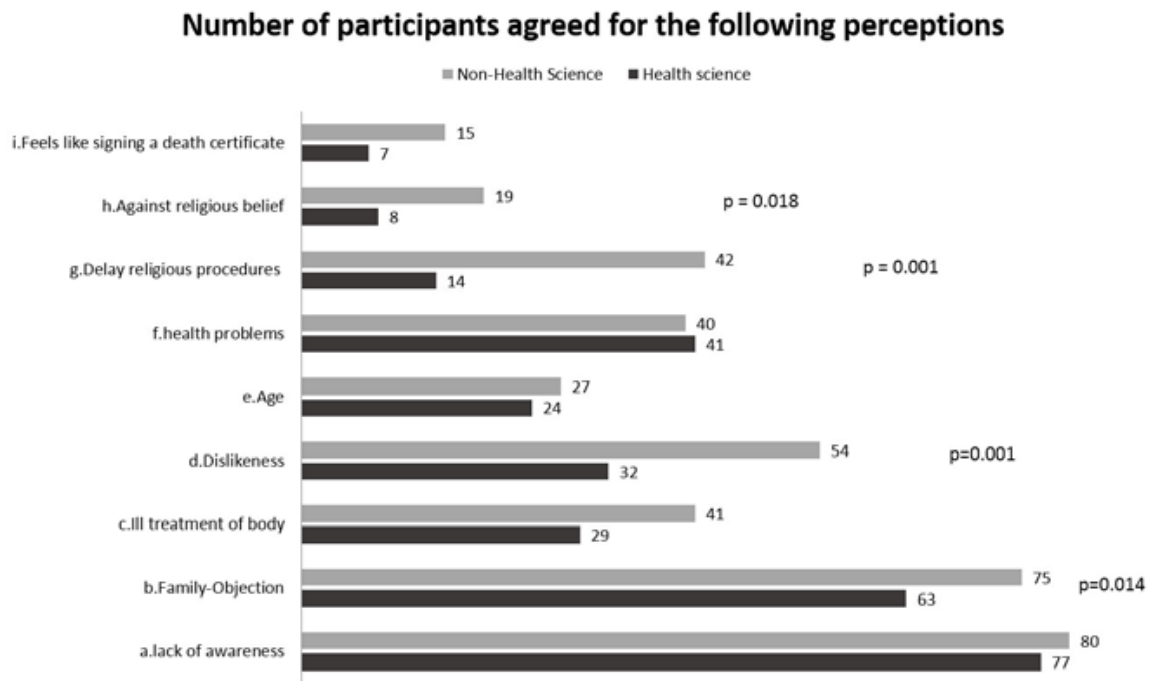

Fig. 2. Difference in perception towards eye donation. This bar diagram explains the difference in perception regarding the donation of eyes among the health-science and non-health-science groups. Among various perceptions, a significant difference between the two groups was found for four perceptions for which the $p$-value is mentioned. 
Table 4. Univariate analysis showing association between willingness to donate and other variables.

\begin{tabular}{|c|c|c|c|}
\hline & Parameter & Odds ratio $(95 \% \mathrm{CI})$ & P-value \\
\hline \multirow{2}{*}{ Nature of profession } & Non-health science & 1 & - \\
\hline & Health Science & $2.158(1.073,4.321)$ & 0.031 \\
\hline \multirow{2}{*}{ Age } & $>50$ years & 1 & \\
\hline & $\leq 50$ years & $1.201(0.557,2.59)$ & 0.641 \\
\hline \multirow{2}{*}{ Gender } & Males & 1 & - \\
\hline & Females & $1.558(0.746 .3 .251)$ & 0.238 \\
\hline \multirow{4}{*}{$\begin{array}{l}\text { Educational } \\
\text { qualification }\end{array}$} & Diploma & 1 & - \\
\hline & Bachelors & $2.25(0.251,20.202)$ & 0.469 \\
\hline & Masters & $5.091(0.579,44.74)$ & 0.142 \\
\hline & $\mathrm{PhD}$ & $8.002(0.624,102.64)$ & 0.110 \\
\hline
\end{tabular}

In the perception domain, those who agreed/strongly agreed were grouped as ' 2 ' and those who disagreed/strongly disagreed were grouped as ' 1 '. When we analyzed the effect of perception of willingness about eye donation using logistic regression after adjusting for qualification and nature of profession (health science/ non-health science), we found that people who disagree/strongly disagree, the negative perceptions such as 'Family members object to eye donation' (odds: 3.75, $\mathrm{p}=0.030,95 \% \mathrm{Cl}(1.14,12.39))$, 'Dislike of separating eye from the body' (odds:7.02, $\mathrm{p}=0.006,95 \% \mathrm{Cl}(1.73,28.42))$ and 'Donating an organ is against my religious belief' (odds: $8.51, \mathrm{p}=0.039,95 \% \mathrm{Cl}(1.11,65.09)$ ) and the study participants showed higher chance of saying 'yes' for eye donation.

\section{Discussion}

Even though there was no significant difference in awareness level between health science and non-science professionals in the present study, the knowledge level was significant between the two groups. Regarding the fact that eyes could be donated only after death, the awareness level was $96 \%$ among nursing ${ }^{15}$ students and $33 \%$ among medical students. ${ }^{13}$ In the present study, $80 \%$ of both health science and non-science professionals were aware that eyes can be donated only after death. The reason for this high awareness could be urban population, which is supported by the study done by Dandona et al. ${ }^{4}$ and Krishnaiah et al. ${ }^{11}$ who state that the awareness amongst the urban population is $70 \%$ and amongst the rural population $30 \%$. In a study done by Dhaliwal et al. in the Indian population there was no significant difference in awareness between medical and non-medical students. ${ }^{6}$

In a study done by Krishnaiah et al. in a rural population in India, awareness 
Knowledge, awareness, perception, and willingness towards eye donation among the literate working population

about eye donation was poorer among females. ${ }^{11}$ Our study shows no difference in awareness level across gender, which could be mostly due to urban participants and higher education level. In another study done among health professionals in India, 59.2\% had good knowledge about eye donation, ${ }^{9}$ but in our study only $41 \%$ of health science professionals had good knowledge. In their study, knowledge was poor among females compared to males ${ }^{9}$ and they also report no significant difference in knowledge levels between males and females among health science and non-health science professionals.

In a study done among attendants of patients in Malaysia, a higher level of education showed a positive impact on the awareness of eye donation but did not show any statistically significant effect on the willingness to donate eyes..$^{12}$ In our study, a higher level of education showed a positive impact on willingness towards eye donation.

According to a study by Shahbazian et al., age, sex, and occupation did not influence the attitude; however, ethnicity, educational level, economic status, and having a loved one in need of an organ significantly increased the willingness for organ donation. ${ }^{14}$ In our study, we found that health science professionals with a higher educational qualification had twice the chance of showing their willingness towards eye donation compared with non-health science professionals. Although the age, gender, and educational status were matched between the study groups, better knowledge among the health science professionals represents the higher knowledge and exposure to clinical aspects and care.

In our study, gender showed variation in willingness towards eye donation: females were more willing to donate eyes than males, but this was not statistically significant. Willingness to donate an eye to close relatives was $37 \%$ among firstyear Malaysian medical students and it was $75 \%$ among final-year Indian medical students. However, none of them marked 'Yes' for the question regarding willingness to donate an eye to close relatives after death.

Willingness towards eye donation was evaluated in many studies. A study among Singapore adults showed that $67 \%$ of participants was willing to donate their eyes. Eighty-four percent of adults showed willingness to donate their eyes in a study done among the urban population in India. In our study, only $25 \%$ showed willingness to donate an eye, even though more than $90 \%$ had good awareness.

According to our study, participants'lack of awareness was perceived as the major reason for people not donating an eye. Another study on nursing students reported that dislike of separating eyes from the body $(67 \%)$ was the major reason for not donating eyes, followed by lack of awareness $(42.8 \%) .{ }^{15}$ In our study, we compared the difference in perception among health science and non-health science professionals and it was significantly different for some factors. In particular, non-health science professionals agreed on the fact that eye donation is against religious beliefs. They also strongly agreed that disliking to separate the eye from the body and family objection are the major reasons for not donating eyes.

Mass media, including newspapers and television, were considered as the major source of information about eye donation in our study, which is similar to other 
studies. In our study, some have suggested to include organ donation in the school curriculum to improve the awareness and to build a positive attitude among children.

Even though more than $90 \%$ of the population had good awareness, only $21 \%$ of the health science professionals had knowledge above $50 \%$. However, only $3 \%$ of the health science professionals filled out the pledge form. None of the non-health science participants filled out the pledge form. Saying 'Yes' in a questionnaire does not show an actual willingness towards eye donation. In our study we could determine the actual willingness by counting those who included the pledge form with the questionnaire. Seventy percent of the participants returned the questionnaire without the pledge form; this means that a huge population is not willing to pledge their eyes. This is an indirect measure to assess action compared to willingness, which signifies that health literacy might be high but behavioral actions appear to be different. Most of the eye donation awareness content focuses on the knowledge aspect and predominantly does not involve the user in the process of improving their perceptions and behavior. There is a requirement of eye donation based health literacy content to incorporate media activation process and ensure active participation among user groups. ${ }^{16}$ It might also be important to develop content to suit the user group (health science and non-health science), rural or urban, and also gender specific.

\section{Conclusion}

Even though the awareness level was not significantly different between health science and non-health science professionals, their knowledge and perceptions about eye donation was significantly different. Non-health science professionals strongly agree on most of the disbeliefs or myths about eye donation. Educational qualification and the perception of eye donation to be against religious beliefs as well as disliking to separate the eye from the body showed significant effect on willingness to donate eyes. More campaigns need to be conducted among illiterates and people with basic education to improve the perception about eye donation rather than focusing on awareness and knowledge.

\section{References}

1. Pascolini D, Mariotti SP, Pokharel GP, et al. 2002 global update of available data on visual impairment: a compilation of populationbased prevalence studies. Ophthalmic Epidemiol 2004;11:67-115.

2. Saini JS, Reddy MK, Jain AK, et al. Perspectives in eye banking. Indian J Ophthalmol 1996;44:47-55.

3. Silva H. The Sri Lanka experience in eye banking. Refract Corneal Surg 1991;7:463-465.

4. Dandona R, Dandona L, Naduvilath TJ, McCarty CA, Rao GN. Awareness of eye donation in an urban population in India. Aust N Z J Ophthalmol 1999;27:166-169.

5. Saini JS. Realistic Targets and Strategies in Eye Banking. Indian J Ophthalmol 1997;45:141-142.

6. Dhaliwal.U. Enhancing eye donation rates, Training students to be motivators. Indian J Ophthalmol 2002;50;209-212.

7. Priyadarshini B, Srinivasan M, Padmavati A, et al. Awareness of eye donation in an adult population of southern India. A pilot study. Indian J Ophthalmol 2003;51:101-104. 
8. Yew YW, Saw SM, Pan JC, et al. Knowledge and beliefs on corneal donation in Singapore adults, Indian J Ophthalmol 2004;52:82-88.

9. Gogate B, Gogate P, Khandekar R, et al. Knowledge of and Attitudes towards Eye Donation among Health Professionals in India. Asian J Ophthalmol 2008;3:171-173.

10. Abuksis G, Orenstein S, Hershko A, et al. Cornea recipients: are their opinions and attitudes toward organ donation different from those of the general population? Transplantation Proceedings 2004;36(5):1249-1252.

11. Krishnaiah S, Kovai V, Nutheti R, et al. Awareness of eye donation in the rural population of India. Indian J Ophthalmol 2004;52:73-78.

12. Bhandary S, Khanna R, Rao K, et al. Eye donation - Awareness and willingness among attendants of patients at various clinics in Melaka, Malaysia. Indian J Ophthalmol 2011;59:41-45.

13. Bharti MK, Reddy SC,Tajunisah I, Ali NA. Awareness and knowledge on eye donation among university students. Med J Malaysia 2009;64:41-45.

14. Shahbazian H, Dibaei A, Barfi M. Public attitudes toward cadaveric organ donation: $A$ survey in Ahwaz. Urol J 2006;3:234-239.

15. Gupta A, Jain S, Jain T, Gupta K. Awareness and perception regarding eye donation in students of a nursing college in Bangalore. Indian J Community Med 2009;34:122-125.

16. Chesterton P. Evaluation of the Meena communication initiative. Kathmandu: UNICEF 2004. 


\section{Appendix I - Questionnaire}

Questionnaire to assess the Knowledge, Awareness and Perception towards eye donation.

\section{Part 1}

1. Have you heard about eye donation? (Yes / No). If YES move to Question no. 2; if NO then move to question no. 3.

2. How did you come to know about eye donation? (Mass media / Hospital / Family doctor / Friend / Organ donation campaigns / During this survey / Not sure).

3. Do you think eyes should be donated? (Yes / No / Do not know).

4. Do you know that pledging (promising) of eyes can be done when you are alive? (Yes / No / Do not know).

5. When do you think eyes can be removed for donation? (With CONSENT from a living person / Only after death / Do not know).

6. Have you heard about eye banks? (Yes / No / Do not know).

\section{Part 2}

7. What is transplanted from the donor eye? (Whole eye / Front layer of the eye/ Back layer of the eye / Do not know).

8. Within how much time after death should the eyes be removed? (Within 6 hrs / Within 12 hrs / Within 24 hrs / No time limit / Do not know).

9. Can eyes be removed at the donor's house? (Yes / No / Do not know).

10. Can the donated eyes be preserved in the Eye bank? (Yes / No / Do not know).

11. Can persons wearing glasses donate eyes? (Yes / No / Do not know).

12. Can anyone irrespective of blood group be a donor? (Yes / No / Do not know).

13. Is there any age limit for pledging (donating) of eyes? (Yes / No / Do not know); If YES, what is the age limit? years.

14. Can a person with communicable disease (disease that is spread/transmitted easily) can donate his eyes? (Yes / No / Do not know).

15. Does the name of the person who donates the eye and the person who receives the eye remain anonymous? (Yes / No / Do not know).

16. Does the next of kin (first-degree relative) have the right to give the consent for eye donation? (Yes / No / Do not know).

17. Do you think that 'CONSENT' for donating eyes should be
a) Mandatory and willed before death by the donor;
b) Mandatory, but after death by an adult family member;
c) Optional at the discretion of the donor alone;
d) Optional at the discretion of an adult family member;
e) Do not know.

18. If you wish to donate your eyes, whom do you approach? (Hospital / Doctor / Relatives / Eye bank / Do not know).

19. Name any eye bank that you know in India. 
Knowledge, awareness, perception, and willingness towards eye donation among the literate working population

\section{Part 3}

20. Are you willing to donate your eyes? (Yes / Not sure / Need time to decide / No).

21. In case of your close relative's death, would you be willing to donate their eyes?

(Yes / Not sure / Need time to decide / No).

22. Following is a list of possible reasons for NOT donating eyes. Please indicate how much you agree on EACH based on your perception using the options given below (please tick the appropriate boxes).

\begin{tabular}{|c|c|c|c|c|c|c|}
\hline & & 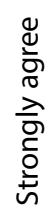 & 这 & $\begin{array}{l}\frac{\bar{d}}{d} \\
\frac{0}{0} \\
\frac{0}{0} \\
\frac{0}{\partial}\end{array}$ & 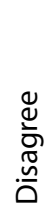 & 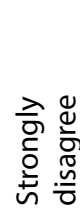 \\
\hline $\mathbf{a}$ & Lack of awareness about eye donation & & & & & \\
\hline b & Family members object to eye donation & & & & & \\
\hline C & $\begin{array}{l}\text { Feeling that body is ill-treated by eye } \\
\text { donation }\end{array}$ & & & & & \\
\hline d & Dislike of separating eye from the body & & & & & \\
\hline e & $\begin{array}{l}\text { Feeling unsuitable to donate eyes } \\
\text { because of my age }\end{array}$ & & & & & \\
\hline $\mathbf{f}$ & $\begin{array}{l}\text { Feeling unsuitable to donate eyes } \\
\text { because of health problems }\end{array}$ & & & & & \\
\hline $\mathbf{g}$ & $\begin{array}{l}\text { Eye donation will delay funeral and other } \\
\text { religious rites after death }\end{array}$ & & & & & \\
\hline $\mathbf{h}$ & $\begin{array}{l}\text { Donating an organ is against my religious } \\
\text { belief }\end{array}$ & & & & & \\
\hline $\mathbf{i}$ & $\begin{array}{l}\text { Signing an eye donor's card feels like } \\
\text { signing a death certificate }\end{array}$ & & & & & \\
\hline
\end{tabular}

23. Which of the above reasons is MOST APPLICABLE for NOT donating an eye by you? Write the option of the reason $(a, b, c, d, e, f, g, h, i)$

24. How do you think we can increase the awareness about eye donation? 